\title{
İmpakte Distal Üreter Taşı ile Birlikte Ciddi Distal Üreter Darlığının Tedavisinde Endoskopik Distal Üreter İnsizyonu ve Lazer Litotripsi
}

\author{
Burak Köprü ${ }^{1}$, Zafer Demirer², Hasan Cem Irkılata ${ }^{1}$
}

${ }^{1}$ Gülhane Askeri Tıp Akademisi, Üroloji Anabilim Dalı, Ankara

Eskişehir Asker Hastanesi, Eskişehir

\section{Giriş}

$\ddot{U}$ riner sistem taş hastalığ toplumda sık görülen bir durumdur. Semptomatik taşların büyük bir kısmı üreterde saptanan taşlardır ve çoğunlukla böbrekte oluşup daha sonra üretere yerleşirler. Birçok üreter taşı spontan olarak düşer (1). Bir çalışmada $5 \mathrm{~mm}$ 'nin altındaki distal üreter taşlarının spontan düşme oranı \%71-98 olarak bildirilmiştir (2). Üreter taşlarının tedavisinde üreterorenoskopi (URS) ve şok dalga litotripsi (ESWL) ana tedavi modaliteleridir. Ancak özellikle orta ve distal üreter taşlarında en uygun tedavi seçeneği URS iken, ESWL sadece $1 \mathrm{~cm}$ 'den küçük proksimal üreter taşlarında ilk olarak tercih edilir (3).

İmpakte üreter taşı, 1 aydan daha uzun süre üreterde ayn pozisyonda duran, endoskopik olarak taşın kenarından bir kılavuz telin geçmediği veya intravenöz ürografide taşın ilerisinde kontrast medyumun vizüalize olmadığı durum olarak tanımlanır. Genellikle üreterin anatomik darlık bölgelerinden (üreteropelvik bileşke, iliak damarların çaprazland1$\breve{g}_{1}$ bölge, üreterovezikal bileşke) birinde lokalize olurlar. İnce kalibreli veya fleksıbl üreteroskopların gelişimi ve holmium: yttrium-aluminum-garnet (Ho:YAG) lazerin kullanımı ile impakte üreter taşlarının tedavisinde URS ile intrakorporeal litotripsi en etkili ve güvenli tedavi modalitesi haline gelmiştir.

Bu olgu sunumumuzda $2 \mathrm{~cm}$ 'den büyük impakte distal üreter taşının tedavisinde kullanılan yardımcı bir endoskopik cerrahi yöntem hakkında deneyimimizi paylaşmayı amaçladik.

\section{Olgu Takdimi}

Yaklaşık 3 aydan beri sağ yan ağrısı olan 54 yaşında kadın hastanın 1 ay önce başka bir merkezde çekilmiş olan direk üriner sistem grafisi (DÜSG)'nde sağ üreter distaline uyan taş izlenmiş ve üriner ultrasonografi (US)'de 4.derece hidronefroz saptanmıştır. Aynı merkezde 1 seans ESWL tedavisi uygulanmasına rağmen fayda görmeyen hasta polikliniğimize başvurdu. Hastanın merkezimizde çekilen DÜSG'nde sağ üreter alt uça uyan yaklaşık $2.5 \mathrm{~cm}$ boyutunda distal üreter taşı tespit edildi. (Resim 1A). Üriner US 4.derece hidroüreteronefrozun devam ettiğini teyid etti (Resim 1B). Taşın boyutu ve lokalizasyonu göz önüne alınınca hastaya URS eşliğinde lazer litotripsi yapılmasına karar verildi.

Genel anestezi sonrası litotomi pozisyonunda hastaya semi-rijid üreterorenoskop ile girildi. Sağ üreter orifisinin ileri derece dar olduğu ve distal üreterdeki taşın mesane içine doğru bir kabarıklığa neden olduğu gözlendi (Resim 2A). Sağ üreter orifisine kılavuz tel gönderilmeye çalışıldı ancak
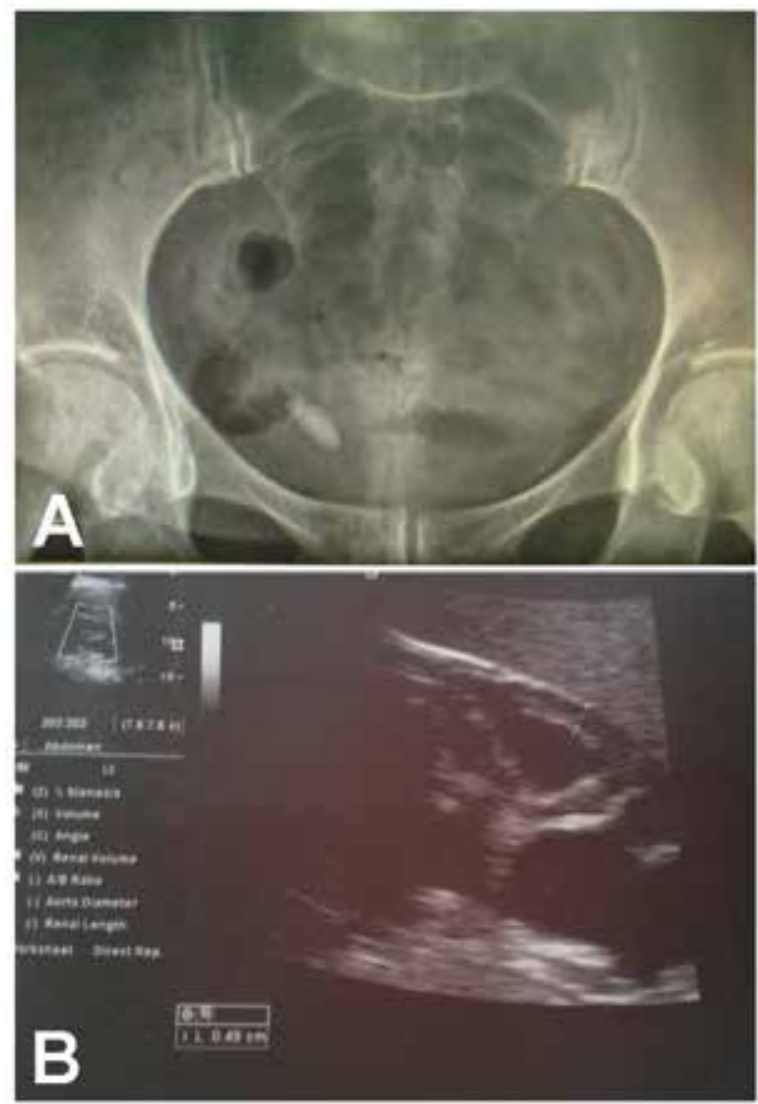

Resim 1: Preoperatif değerlendirmede; A. Direk üriner sistem grafisinde distal üreter taşına uyan opasite izlenmekte, B. Üriner ultrasonografide 4.derece hidroüreteronefroz görülmekte 


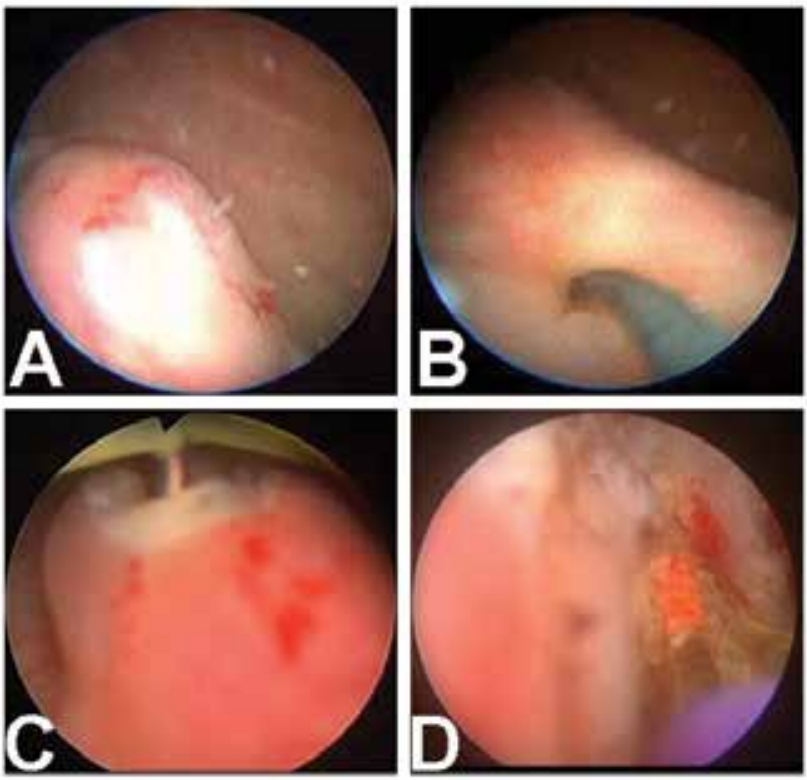

Resim 2: Endoskopik yaklaşımda; A. Sağ üreter taşının mesane içerisine doğru oluşturduğu protrüzyon izlenmekte, B. Sağ üreter orifisindeki ileri derece darlık nedeniyle rehber telin geçmediği görülmekte, $C$. Distal üreterin endoskopik olarak insizyonu, D. Distal üreterdeki taşa üreteroskopik Ho:YAG lazer litotripsi uygulanması

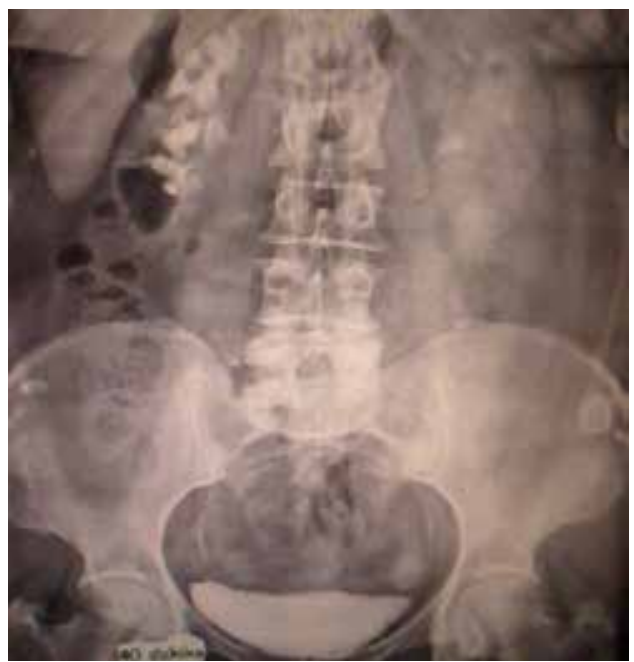

Resim 3: Postoperatif 3.ayda çekilen intravenöz pyelografide sağ üreter akımının normal olduğu ve sağ pelvikaliseal sistemdeki daha önceki obstrüksiyona sekonder değişiklikler izlenmekte.

üreter orifisinin ileri derece dar olması nedeniyle ve taşın distal üretere impakte olması nedeni ile girilemedi (Resim 2B). Bunun üzerine üreterorenoskop çıkılıp 24 F rezektoskop ile girildi. Sağ üreter orifisinin hemen üzerinde taşa bağlı oluşan kabarıklık üzerine üreter trasesi boyunca yaklaşık 1 cm'lik insizyon uygulandı (Resim 2C). Böylece taş görünür hale geldi ve taş lazer litotriptör yardımı ile fragmente edildi (Resim 2D). Fragmente parçalar dışarı alındı. Hastaya kılavuz tel üzerinden 6F $28 \mathrm{~cm}$ D-J kateter kondu. Post operatif dönem komplikasyonsuz geçti. D-J kateter 1 ay sonra çekildi. Hastanın 3 ay sonra çekilen intravenöz pyelografisinde sağ distal üreter akımının neredeyse normal kalibrede olduğu ve sağ böbrekteki hidronefroza bağlı sekonder değişikliklerin kısmen devam ettiği izlendi (Resim 3). Dinamik böbrek sintigrafide diüretik uygulamasına tam yanıt veren, pelvikaliseal stazlı, diferansiyel fonsiyona katkısı \%37,8 olan sağ böbrek belirlenmiştir.

\section{Tartışma}

Aslında çoğu zaman taşın ne zaman impakte olduğunu belirlemek de zordur. İmpakte üreter taşı, hastanın taş varlığını hissetmemesi ve buna bağlı tedavide gecikme ile taş çevresinde enfeksiyon, kronik inflamasyon ve ödem ihtimalini arttırır. Histolojik olarak impaksiyon bölgesindeki üreterde kronik inflamasyon ve ödem uzun dönemde interstisyel fibrosis ve üretelyal hipertrofiye neden olur. Kronik basınç ve taş materyaline karşı immünolojik reaksiyon iskemiye neden olarak sürece katkıda bulunur. Sonuçta uzun dönemde gelişen üreteral striktür bu hastalarda izlenen en önemli komplikasyondur. Üreteral striktür birlikteliği \%14-44 olarak rapor edilmiştir. Daha nadir izlenen bir diğer komplikasyon da kronik irritasyona bağlı gelişen üreteral poliplerdir.

Büyük impakte üreter taşlarının tedavisinde son 20 yılda açık üreterolitotominin yerini minimal invaziv cerrahi teknikler almıştır. Her ne kadar ESWL tedavisi impakte üreter taşlarının tedavisinde uygulanmışsa da; taş etrafında bir genişleme alanı olmaması nedeniyle başarı oranı düşüktür. Impakte taşları üreterden manüple etmek oldukça zordur, hatta geri-itme (push back) tekniği de efektif olarak uygulanamaz. Günümüzde impakte üreter taşlarının tedavisinde, hangi seviyede olursa olsun, en etkin yöntem URS eşliğinde litotripsidir. Son yıllarda daha ince semi-rijit üreteroskoplar ve fleksıbl üreteroskop teknolojisindeki ilerleme, pnömotik ve Ho:YAG lazer litotriptörlerin gelişimi ile URS cerrahisinin başarı oranları oldukça iyileşmiş ve komplikasyon oranları düşmüştür.

İmpakte üreter taşlarının URS cerrahisi ile tedavisinde başarı oranları Değirmenci ve ark.ları tarafından distalde \%95.7, ortada \%88.8 ve proksimalde \%81.8 olarak rapor edilmiştir (5). Binbay ve ark.ları URS litotripside toplam başarı oranını pnömotik litotriptör kullanımında \%80, Ho:YAG lazer kullanımında \%97.5 olarak rapor etmişlerdir (6). Değirmenci ve ark.ları pnömotik ve Ho:YAG lazer kullanımını karşılaştırdıkları bir diğer çalışmalarında başarı oranlarını pnömotik için distalde $\% 91.7$, proksimalde $\% 67.9$ olarak ve Ho:YAG lazer için distalde $\% 96.8$ ve proksimalde $\% 94.4$ olarak rapor etmişlerdir (7).

İmpakte üreter taşlarının URS cerrahisinde komplikasyonlar Clavien sınıflamasına göre değerlendirilmektedir. Değirmenci ve ark.ları komplikasyon oranlarını pnömotik litotripsi sonrası \%13.6'sında 1 veya 2.derece, \%15.4'ünde 3 veya 4.derece, Ho:YAG lazer sonrasi \%15.9'unda 1 veya 2.derece, \%7.1'inde 3 veya 4.derece olarak rapor etmişlerdir (7). Komplikasyonlar açısından en önemli risk faktörleri, operasyon süresi, taş yükü (boyutu), taş lokasyonu, tekmultipl taş varlığıdır $(5,7)$.

Bizim olgumuzda her ne kadar URS ve Ho:YAG lazer litotripsi ile taş frakmantasyonu sağlanmışsa da; distal üreterdeki ciddi darlık ilk aşamada üreteroskop ile taşa ulaşımı engellemiştir. Ayrıca üreter orifisindeki ileri derece darlık bir 
rehber telin bile geçişine müsaade etmemiştir. Taşın boyutu, yeri ve mevcut cerrahi ekipmanlar göz önüne alındığında açık cerrahi yerine minimal invaziv endoskopik yaklaşım tercih edilmiştir. Üreterin mesane içerisindeki distal kısmında taşa ait kabarıklığın izlenmesi nedeniyle üreterosel insizyonuna benzer bir insizyon ile taşa erişim sağlanmıştır. Sonrasında ise tamamen impakte olan distal üreterdeki taş Ho:YAG lazer litotripsi ile tedavi edilmiştir.

Sonuç olarak distal üreterde büyük impakte taş ile birlikte rehber tel eşliğinde girişe izin vermeyen distal üreteral striktür varlığında, endoskopik distal üreter insizyonu ile URS Ho:YAG lazer litotripsi tedavi yaklaşımın uygun bir tedavi olduğunu düşünmekteyiz.

\section{Kaynaklar}

1. Miller OF, Kane CJ. Time to Stone passage for observed ureteral calculi: a guide for patient education. J Urol 1999, 162(688-90).

2. Segura JW, Preminger GM, Assimos DG, et al. Ureteral stones clinical guidelines panel summary report on management of ureteral calculi. J Urol 1997; 158:1915-21.

3. Türk C, Knoll T, Petrik A, Sarıca K, Straub M, Seitz C. Guidelines on Urolithiasis.
4. Timothy G. Schuster, Brent K. Hollenbeck, Gary J. Faeber and J Stuart Wolf JR. Complications of Ureteroscopy: Analysis of predictive factors. J Urol 2001; Vol. 166 538-540.

5. Degirmenci T, Gunlusoy B, Kozacioglu Z, Arslan M, Kara C, Koras O, Minareci S. Outcomes of ureteroscopy for the management of impacted ureteral calculi with different localizations. Urology. 2012 Oct;80(4):811-5.

6. Binbay M, Tepeler A, Singh A, Akman T, Tekinaslan E, Sarilar O, Baykal M, Muslumanoglu AY. Evaluation of pneumatic versus holmium:YAG laser lithotripsy for impacted ureteral stones. Int Urol Nephrol. 2011 Dec;43(4):989-95.

7. Degirmenci T, Gunlusoy B, Kozacioglu Z, Arslan M, Koras O, Arslan B, Minareci S. Comparison of Ho:YAG laser and pneumatic lithotripsy in the treatment of impacted ureteral stones: an analysis of risk factors. Kaohsiung J Med Sci. 2014;30(3):153-8.

Yazışma Adresi:

Hasan Cem Irkulata,

Gülhane Askeri Tıp Akademisi, Üroloji Anabilim Dalı, 06018, Etlik, Ankara

Tel: +903123045611

e-mail:hcirkilata@hotmail.com 